\title{
Work tool-related eye injuries: Helsinki Ocular Trauma Study
}

\author{
Ahmad Sahraravand (1) - Anna-Kaisa Haavisto · Päivi Puska · Tiina Leivo
}

Received: 27 April 2019/Accepted: 18 November 2019/Published online: 6 December 2019

(C) The Author(s) 2019

\begin{abstract}
Purpose To quantify and characterize the epidemiology, treatments, long-term outcome, and use of resources for work tool-related eye injuries and their severity.

Methods We included all new patients with a work tool-related eye injury treated at the Helsinki University Eye Hospital in 1 year. The data were from hospital records, examinations, and patient questionnaires. The follow-ups were at 3 months and 6 years. Results Work tools caused 3\% (37/1151) of all eye injuries. The mean age was 37 and $84 \%$ were men. Most injuries (84\%) occurred at work (17) or at home (15). There were 14 minor injuries, 12 contusions, 9 open globe injuries (OGI), and 2 eyelid wounds. The annual incidence of work tool-related eye injuries was 2.4/100,000 and hospitalization 0.6/100,000. At 6-year follow-up, we re-examined 18 patients and 17 were interviewed by phone. Four patients were blinded. We recorded 690 sick leave days and 43 major operations. No traumatic glaucoma was diagnosed. Fifteen patients needed lifelong follow-up. Permanent impairment occurred in $30 \%$ (11) of work tool-related eye injuries, from whom, nine were
\end{abstract}

A. Sahraravand $(\square) \cdot$ A.-K. Haavisto .

P. Puska · T. Leivo

Ophthalmology, Helsinki University Hospital, University

of Helsinki, Haartmaninkatu 4 C, 00290 Helsinki, Finland

e-mail: asahra78@gmail.com;

ahmad.sahraravand@hus.fi caused by manual tools. Work tools comprised $10 \%$ of the permanently impaired, but $2.5 \%$ of the nonpermanently impaired cases among all eye injuries (1151).

Conclusion The proportional difference between the permanently impaired and the non-permanently impaired was higher in work tool-related eye injuries than other causes reported in previous Helsinki Ocular Trauma Studies. High-risk injuries were mainly caused by manual tools and nails and resulted in OGI.

Keywords Contusion - Epidemiology · Eye injury · Manual tools · Open globe injury · Work tools

\section{Introduction}

Eye injuries are a major source of monocular low vision and blindness. Tools used at work, at home, and during leisure time are a significant cause of mostly preventable eye injuries, resulting in lifelong complications. Here, we use the term "work tool" to define a manual or power tool or related equipment needed as a means for working in construction, maintenance, or household chores either outdoors or indoors. To our knowledge, there are no long-term recent follow-up studies in the literature focused exclusively on a range variety of work tool-related eye injuries. In Scotland, tools or machinery used either at home $(14 \%)$ or at 
work (10\%) was in 1996 collectively (24\%) the most frequent cause among 417 patients and in 2015, the second most common cause (21\%), among 102 patients of serious eye injuries [1, 2]. In the USA, objects and machinery were the largest contributor $(30 \%=5487)$ of eye trauma as a primary diagnosis in children [3]. Additionally, cutting and construction tools were the largest consumer product $(\mathrm{CP})$ group $(33 \%=7384)$, among 25-64-year-olds, and second largest $\mathrm{CP}$ group $(21 \%=277)$ among elderly patients ( $>65$ years) to cause eye injury $[4,5]$. In industrial accidents in Finland in 1984, 26\% of compensated eye injuries were caused by hand tools and $5 \%$ by other equipment and constructions [6]. We previously reported that in Southern Finland, of all eye injuries (1151) resulting in permanent impairment (107), the proportion caused by work tools was $11 \%(8 / 73)$ among adults, $13 \%$ (2/15) among the elderly, and $11 \%$ (2/19) among children [7-9]. However, the current characteristics of work tool-related eye injuries, as we describe in this study, are not addressed elsewhere. The few studies are either limited reports of work tools as one cause among other causes of eye injuries [1-9] or have concentrated solely on occupational injuries and are outdated [6-10] or have focused on specific particular work tools $[11,12]$. This study seeks to expand the knowledge of the work tools associated with eye injury by focusing on identifying the highrisk, injury-causing work tools, and the outcomes after a six-year follow-up. We also present the differences between work tool-related eye injuries and other major causes of eye injuries in terms of frequency and seriousness. This study may have important implications for the prevention of work tool-related eye injuries.

\section{Materials and methods}

The population under study consisted of all new patients injured by work tools and treated at the Helsinki University Eye Hospital (HUEH) emergency department in 1 year (1 May 2011 to 30 April 2012). During the first visit, all new ocular trauma patients received a questionnaire (Table 1) eliciting detailed information about the trauma-causing event. If the questionnaire was not completed, researchers collected background data from the hospital records. We recorded age, gender, laterality, possible previous amblyopia, detailed status findings at the first presentation, diagnoses, and treatments from the hospital database. If several injuries were present in the eye or its vicinity, the clinically most significant trauma diagnosis (ICD-10 S- or T-diagnoses) was recorded as the primary diagnosis, and the injuries were divided into diagnosis groups according to this. Accidents, in which the causative agent did not meet the definition of "work tools" described above and was outside of this study's defined inclusion criteria, were excluded.

During the first three-month follow-up, we recorded the visual acuity (VA), the intraocular pressure (IOP), and the main abnormal status findings. The severity of the ocular trauma was evaluated using the estimated need for lifelong follow-up, performed major surgery and future surgery, permanent abnormal VA, and other functional visual symptoms or findings.

In the second stage of the follow-up, 6 years after the eye injury, the clinical examination included the best-corrected visual acuity (BCVA), IOP (Goldmann applanation tonometry or ICare tonometer (Icare TA01i, Icare Finland Oy, Finland)), gonioscopy, slitlamp biomicroscopy, and dilated fundus examination. The patients also underwent the following examinations, needed for diagnosis of glaucoma: 1 . visual field (VF) examination by the Octopus G Standard Dynamic program (Octopus 900, SN 833, V 2.3.0/ 3.3.1, Haag-Streit AG, Bern, Switzerland); 2. thickness measurements of the peripapillary nerve fiber layer (NFL), the optic disk nerve head, and the ganglion cell layer using the optical coherence tomography (OCT) (Cirrus-1 SW Ver 6.0.2.81, Copyright 2012, Carl Zeiss Meditec, Inc, Germany); 3. stereo disk and 4. fundus NFL photography (Carl Zeiss, Germany). All the glaucoma examinations were reviewed by the authors, Sahraravand (ophthalmologist) and Puska (a senior glaucoma consultant). Patients who could not attend the clinical examinations were interviewed by phone.

We made a structured interview for all the patients (Table 1). We analyzed the data, presented the distributions (Excel, Microsoft Office 2013, Microsoft, Redmond, WA), and calculated the percentages from the reported results. For the incidence calculations, we estimated the average population living in the HUEH district in 2011-2012 $(1,553,915)$ [13] to be the population at risk. We estimated the resource use by the number of outpatient visits, the duration of hospitalization, the number of operations performed, 
Table 1 The questionnaires at the first presentation in emergency department (ED) and at 6-year follow-up

Questions at presentation at first visit in the ER

1. Date and time of eye injury.

2. Where did the accident occur? (at work, in home, school, place for sports, in the road, other, where?)

3. Was the accident caused intentionally/unintentionally?

4. Did alcohol or other drugs have a role in the accident? If yes, who was under the influence of them? (yourself, others, all parts)

5. What happened and what hit the eye?

6. Did you use any eye protection during the eye injury? (yes/no)

The structured interview at 6-year follow-up

1. Do you feel your vision has deteriorated in the injured eye due to the injury?

2. Do you have any of the following visual deteriorations due to the eye injury: blurriness, difficulty focusing, diplopia, floaters, glare, scotomas, or watery eyes?

3. If you have any of previous visual deteriorations, are they occasional or continuous in nature?

4. Do you use any ophthalmic medication due to the eye injury?

5. Rate the possible remaining pain in your injured eye. (NRS = Numeric Rating Scale: $0=$ no pain, $1=$ mild or occasional pain, $2=$ moderate but tolerable pain, $3=$ intense pain, and $4=$ the worst possible pain).

6. Rate the possible subjective aesthetic impairment due to the eye injury by NRS: $(0=$ no aesthetically impaired, $1=$ mildly impaired, 2 = moderately impaired, $3=$ substantially impaired, and $4=$ subjectively the worst possible aesthetic impairment)

and the need for sick leave or activity restriction. If sick leave or activity restriction was not recorded, their need was estimated on the basis of clinical findings and international recommendations [14-17]. We estimated a need for lifelong follow-up among those with considerable symptoms and those with a history of hyphema, lenticular/iris damage, or angle recession. VA $<20 / 40$, because of the trauma, was categorized as impaired, and legal blindness was defined as VA $<20 / 200$. We evaluated the injured eye being permanently impaired when the VA was estimated to be permanently impaired $(<20 / 40)$, or when the patient had subjective visual or functional symptoms, substantial or continuous in nature according to the structured questionnaire asked from the patients (Table 1). To analyze the gravity of the work toolrelated eye injuries, we compared the percentages of all the permanently impaired cases and all the nonpermanently impaired cases in the Helsinki Ocular Trauma Studies with each other to determine which cause-group produced proportionately more severe cases [7-9, 18]. We performed statistical analysis using program $\mathrm{R}$ version 3.5.0. We used Fisher's exact test and two-sample test for equality of proportions with continuity correction and calculations.
Our study was approved by the Ethics Committee of the Helsinki-Uusimaa Hospital District and followed the tenets of the Declaration of Helsinki.

\section{Results}

Work tools caused $3.2 \% \quad(=37 / 1151)$ of the eye injuries during the years under study. The annual incidence of work tool-related eye injuries was 2.4/ 100,000 population. Ten patients (10/37) were hospitalized. The incidence of hospitalization was $0.64 /$ $100,000 /$ year. Three patients were children aged 2-11. Thirty patients were adults (aged 17-60), and four patients were over 60 years old. The mean age of patients was 37 (median 35, range 2-71). As Table 2 shows, the male-female ratio was 31:6. Manual tools and related equipment caused 27 and powered tools and related equipment caused 10 eye traumas. Nails were the most common cause of eye trauma. Most of the incidences took place at work $(n=17)$ and at home $(n=15)$. Two accidents occurred in a garage, and one in school trip, and the place of injuries of two cases were not available. Work tools caused 14 minor injuries, 12 contusions, nine open globe injuries 
Table 2 Cause, diagnosis, group, gender, and place of work tool-related eye injuries

\begin{tabular}{|c|c|c|c|c|c|c|c|c|c|c|c|c|c|}
\hline \multirow[t]{2}{*}{ Tools $^{\mathrm{a}}$} & \multirow[t]{2}{*}{$n,(\%)$} & \multicolumn{2}{|c|}{ Tool group ${ }^{b}$} & \multicolumn{4}{|c|}{ Diagnosis group $^{c}$} & \multicolumn{2}{|c|}{ Gender $^{\mathrm{d}}$} & \multicolumn{4}{|c|}{ Place of injury ${ }^{e}$} \\
\hline & & Manual & Group & Minor & Contusion & OGI & Wound & M & $\mathrm{F}$ & Work & Home & NA & Other \\
\hline Nail & $\begin{array}{l}5, \\
(13.6)\end{array}$ & 5 & & & 2 & 3 & & 5 & & 3 & 2 & & \\
\hline Screwdriver & $\begin{array}{l}\text { 4, } \\
(10.8)\end{array}$ & 4 & & 2 & & 1 & 1 & 4 & & 2 & 1 & & 1 \\
\hline Screw & $3,(8.1)$ & 3 & & 2 & & 1 & & 3 & & 1 & 2 & & \\
\hline Hammer & $2,(5.4)$ & 2 & & & 2 & & & 2 & & & 2 & & \\
\hline Knife & $2,(5.4)$ & 2 & & 1 & & 1 & & 1 & 1 & & 2 & & \\
\hline Pipe & $2,(5.4)$ & 2 & & & 1 & & 1 & 2 & & 2 & & & \\
\hline Pliers & $2,(5.4)$ & 2 & & & 1 & 1 & & 2 & & 1 & & 1 & \\
\hline Brush & $1,(2.7)$ & 1 & & & 1 & & & & 1 & & 1 & & \\
\hline Plunger & $1,(2.7)$ & 1 & & 1 & & & & 1 & & 1 & & & \\
\hline Rake & $1,(2.7)$ & 1 & & & 1 & & & 1 & & & 1 & & \\
\hline Steel wire & $1,(2.7)$ & 1 & & 1 & & & & 1 & & 1 & & & \\
\hline Tent poles & $1,(2.7)$ & 1 & & 1 & & & & & 1 & & & & 1 \\
\hline Wood & $1,(2.7)$ & 1 & & & 1 & & & 1 & & & 1 & & \\
\hline Wrench & $1,(2.7)$ & 1 & & & 1 & & & 1 & & & & & 1 \\
\hline Electric cord & $3,(8.1)$ & & 3 & 3 & & & & 3 & & 3 & & & \\
\hline Sew. Needle. & $2,(5.4)$ & & 2 & 2 & & & & & 2 & & 2 & & \\
\hline Band & $1,(2.7)$ & & 1 & & 1 & & & 1 & & 1 & & & \\
\hline $\begin{array}{l}\text { Nail of nail } \\
\text { gun }\end{array}$ & $1,(2.7)$ & & 1 & & & 1 & & 1 & & & 1 & & \\
\hline Clip & $1,(2.7)$ & & 1 & & 1 & & & 1 & & 1 & & & \\
\hline Drill & $1,(2.7)$ & & 1 & 1 & & & & & 1 & & & 1 & \\
\hline Knob & $1,(2.7)$ & & 1 & & & 1 & & 1 & & 1 & & & \\
\hline Tot.n (\%) & $\begin{array}{l}37 \\
(100)\end{array}$ & $27(73)$ & $\begin{array}{l}10 \\
(27)\end{array}$ & $\begin{array}{l}14 \\
(38)\end{array}$ & $12(33)$ & 9 & $2(5)$ & $\begin{array}{l}31 \\
(84)\end{array}$ & 6 & $\begin{array}{l}17 \\
(46)\end{array}$ & $\begin{array}{l}15 \\
(41)\end{array}$ & 2 & $3(8)$ \\
\hline
\end{tabular}

${ }^{\mathrm{a}}$ Tools $=$ The causative work tools $($ Plunger $=$ metal plunger, Wood $=$ wood/timber, Sew. Needle $=$ sewing machine needle, Band $=$ band of strapping machine, Clip $=$ clip of hose for compressed air, Knob $=$ knob of pressure gauge)

b Tool group: manual tools, power tools

${ }^{\mathrm{c}}$ Diagnosis groups according to the primary diagnosis: contusion, minor eye injury, OGI = open globe injury, and eyelid wound. The following secondary diagnoses were recorded: retinal detachments (3), eyelid wounds (2), corneal erosions (2), contusion (1), fracture of facial bone (1), retinal tear (1), and vitreous hemorrhage (1)

${ }^{\mathrm{d}}$ Gender: $M$ male, $F$ female

${ }^{\text {e}}$ Place of eye injury: Home at home, Work at work, NA Not available

(OGI), and two eyelid wounds. The following secondary diagnoses were recorded: three retinal detachments, two eyelid wounds, two corneal erosions, one fracture of facial bone, one retinal tear, and one vitreous hemorrhage. Four of these had OGI and six contusions as their primary diagnoses. One accident occurred in an amblyopic eye. Twenty-one injuries occurred in the right and 16 in the left eye. No binocular traumas occurred. Thirty-one patients reported not wearing and two reported wearing protective eye glasses. No one suffered a second eye injury during the follow-up.

Findings and treatments during the first 3 months $(n=37)$

At the first presentation, eight patients had VA $<20$ / 200. We recorded four tarsal damages (one with 
lacrimal duct tear), eight corneal perforations, 14 corneal erosions, seven microscopic/macroscopic hyphemae, nine irideal traumas, five damaged/dislocated lenses, and four retinal tears/detachments.

At three months, five patients had VA $<20 / 200$. Ten patients had corneal findings (central haze, decompensation, irregularity, edema), six had irideal abnormalities (aniridia, torn iris, synechiae, anisocoria), three had lenticular findings (aphakia, posterior capsule opacity, PCO), and four had retinal complications (atrophy, scar, silicone oil). In the first 3 months, 13 patients had undergone 30 major surgeries (12 corneal operations, five operations on sclera for perforating injury, five eyelid and canalicular operations, three combined vitrectomies and procedures on lens through pars plana, three extended combined procedures on vitreous body and retina, one foreign body extraction from the orbit, and one endoscopy of nose and pharynx). Seven patients were estimated as needing further surgery in the future. Nineteen patients were estimated to need lifelong follow-up, and 11 patients were assessed as having a permanent visual or functional impairment.

At 6-year follow-up

At 6-year follow-up (mean 5.9, median 5.9, range 5.4-6.3), we reached $35 / 37$ patients: 18 for clinical reexamination, and 17 for an interview by phone. The two lost patients were an 18-year-old adult with a contusion, and a 33-year-old adult with an OGI caused by a nail. Four patients had VA $<20 / 200$. Between the follow-ups, one patient suffered retinal ablation and three patients' vision deteriorated. Five patients underwent 13 (re)-operations between follow-ups: one patient had ICL (intra-cameral-lens) + corneal relaxation incision, one patient had a PKP (penetrating keratoplasty) + aniridia IOL (intraocular lens) + revisions of the corneal sutures + strabismus surgery, one patient a silicone oil extirpation + capsulotomy, one patient a vitrectomy for a new retinal detachment, and one patient a retinotomy with injection and extirpation of silicone oil combined with a retinal membranectomy. Two patients refused further surgery (secondary IOL implantation). None of the patients used ophthalmic medication other than moisturizing eye drops.
Outcomes

\section{Findings}

Among the 18 patients re-examined clinically, six had corneal findings (status post-PKP, corneal opacity, neovascularization, band keratopathy, endothelial loss and astigmatism), four had irideal abnormalities (aniridia, anisocoria, iris synechiae), one had partly scarred angle without angle recession, five had lenticular findings (aniridia IOL, aphakia, traumatic cataract), two had retinal findings (scars), and two patients' retina could not be visualized (one due to phthisis, and one due to silicone oil in the $\mathrm{AC}$ and in the vitreous and partly scarred cornea). Table 3 demonstrates more specifically the findings, symptoms, and the evaluation of pain and aesthetic impairment.

None of the re-examined patients were diagnosed with traumatic glaucoma, and all of them had an IOP $<22$. Three patients had relatively decreased values in the Octopus-VF test, but these were not glaucomatous and were explained by opacities in the cornea or in the lens. Similarly, one patient with abnormal ganglion cell layer thickness had normal values in other tests. One patient who had undergone a previous Lasik operation, with a left eye trauma, showed decreased binocular values in OCT examinations, but other results were within the normal limits.

\section{The permanently impaired}

From the 18 clinically re-examined patients at the last follow-up, we estimated six to suffer a permanent visual or functional impairment: four patients due to impaired vision (VA $<20 / 40$ ), and two patients due to objective findings and continuous subjective symptoms. In addition, four patients reported occasional symptoms, mostly floaters, and four had no findings. The remaining four patients had insignificant findings without any reported symptoms.

From the 17 patients contacted by phone as the last follow-up, we estimated four to suffer a permanent visual or functional impairment: three patients due to reported impaired vision (one eviscerated, one with hand motion, and one aphakic), and one patient due to continuous glare and metamorphopsia (Table 3). In addition, three patients reported occasional symptoms, mostly floaters. The remaining ten patients did not 
Table 3 Outcome of permanently impaired work tool-related eye injuries, $(n=11)$

\begin{tabular}{|c|c|c|c|c|c|c|c|c|c|}
\hline \multicolumn{5}{|c|}{ Status at 3 months } & \multicolumn{2}{|c|}{ Status at 6 years } & \multicolumn{3}{|c|}{ Subjective impairment } \\
\hline Tools & $\begin{array}{l}\text { Age, } \\
\text { gender }\end{array}$ & Diagnosis & Operated & $\begin{array}{l}\text { Visual } \\
\text { acuity }\end{array}$ & $\begin{array}{l}\text { Visual } \\
\text { acuity }\end{array}$ & Findings & $\begin{array}{l}\text { Visual } \\
\text { function }\end{array}$ & $\begin{array}{l}\text { Aesthetic } \\
(0-4)\end{array}$ & $\begin{array}{l}\text { Pain } \\
(0-4)\end{array}$ \\
\hline Nail & $33, \mathrm{M}$ & OGI & $\begin{array}{l}\text { Cornea, lens, } \\
\text { vitreous }\end{array}$ & $20 / 22$ & NA* & & & & \\
\hline anail & $40, \mathrm{M}$ & Contusion & Retina $^{\mathrm{b}}$ & $20 / 20$ & NA & & & 0 & 0 \\
\hline Nail & 47, M & OGI & $\begin{array}{l}\text { Cornea, lens, } \\
\text { sclera, vitreous }\end{array}$ & $20 / 200$ & $20 / 400$ & $\begin{array}{l}\text { Aphakia, silicone oil in } \\
\text { the vitreous and in } \\
\mathrm{AC}^{\mathrm{c}}\end{array}$ & $\begin{array}{l}\downarrow \mathrm{VA}^{\mathrm{d}}, \\
\text { rotated, } \\
\text { unclear } \\
\text { image }\end{array}$ & 0 & 0 \\
\hline $\begin{array}{l}{ }^{\mathrm{a}} \text { Nail of nail } \\
\text { gun }\end{array}$ & $7, \mathrm{M}$ & OGI & $\begin{array}{l}\text { Cornea, eyelid, } \\
\text { orbit, retina, } \\
\text { vitreous }\end{array}$ & $\mathrm{LP}^{\mathrm{e}}$ & 0 & $\begin{array}{l}\text { Phthisis, band } \\
\text { keratopathy, corneal } \\
\text { neovascularization }\end{array}$ & $\begin{array}{l}\downarrow \text { VA, watery } \\
\text { in light }\end{array}$ & 0 & 0 \\
\hline Nail & $11, \mathrm{M}$ & OGI & $\begin{array}{l}\text { Cornea, sclera, } \\
\text { anterior } \\
\text { vitrectomy }\end{array}$ & $\mathrm{CF}^{\mathrm{f}}$ & $20 / 16$ & $\begin{array}{l}\text { Dense } \text { PVD }^{\mathrm{g}} \text {, retinal } \\
\text { scars }\end{array}$ & $\begin{array}{l}\text { Disruptive } \\
\text { floaters }\end{array}$ & 0 & 0 \\
\hline a Pliers & $27, \mathrm{M}$ & OGI & $\begin{array}{l}\text { Cornea, lens, } \\
\text { sclera, vitreous }\end{array}$ & $\mathrm{CF}$ & $20 / 50$ & $\begin{array}{l}\text { Aniridic } \mathrm{IOL}^{\mathrm{h}}, \text { post- } \\
\text { PKP }^{\mathrm{j}}\end{array}$ & $\begin{array}{l}\downarrow \mathrm{VA}, \downarrow \mathrm{VF}^{\mathrm{i}}, \\
\downarrow \text { Focus, } \\
\text { Glare }\end{array}$ & 0 & 0 \\
\hline âPliers & $38, \mathrm{M}$ & Contusion & Retina, vitreous & $\mathrm{HM}^{\mathrm{k}}$ & HM & & $\downarrow \mathrm{VA}, \downarrow \mathrm{VF}$ & 0 & 1 \\
\hline Knife & $29, \mathrm{~F}$ & OGI & Cornea & $20 / 29$ & $20 / 66$ & Cataract, iris synechiae & & 4 & 1 \\
\hline $\mathrm{Knob}^{1}$ & $63, \mathrm{M}$ & OGI & $\begin{array}{l}\text { Cornea, eyelid, } \\
\text { sclera }\end{array}$ & 0 & Eviscerated & & $\downarrow V A$ & 2 & 0 \\
\hline Screw & $71, \mathrm{M}$ & OGI & $\begin{array}{l}\text { Cornea, eyelid, } \\
\text { retina, vitreous }\end{array}$ & $20 / 38^{m}$ & NA & & $\begin{array}{r}\text { Unclear } \\
\text { image }\end{array}$ & 1 & 0 \\
\hline${ }^{\mathrm{a} S c r e w d r i v e r}$ & $35, \mathrm{M}$ & OGI & Sclera & $20 / 40$ & $20 / 16$ & $\begin{array}{l}\text { Endothelial loss, bulbar } \\
\text { irregularity }\end{array}$ & $\downarrow$ Focus & 1 & 0 \\
\hline
\end{tabular}

Numeric Rating Scale (NRS) of pain: $0=$ no pain, $1=$ mild or occasional pain, $2=$ moderate but tolerable pain, $3=$ intense pain, and $4=$ the worst possible pain). NRS of aesthetic impairment: $0=$ no aesthetically impaired, $1=$ mildly impaired, $2=$ moderately impaired, 3 = substantially impaired, and 4 = subjectively the worst possible aesthetic impairment)

* Not available

a(re)operated between follow-ups

${ }^{\mathrm{b}}$ Retina operated in 2016, ${ }^{\mathrm{c}}$ anterior chamber

${ }^{\mathrm{d}}$ Visual acuity

${ }^{\text {e}}$ Light perception

${ }^{\mathrm{f}}$ Counting fingers

${ }^{\mathrm{g}}$ Dense, abundant and centrally located membranes due to posterior vitreous detachment disturbing patient's vision

${ }^{\mathrm{h}}$ Intraocular lens

${ }^{\mathrm{i}}$ Visual field

${ }^{\mathrm{j}}$ Penetrating keratoplasty

${ }^{\mathrm{k}}$ Hand motion

${ }^{1}$ Knob of pressure gauge

${ }^{\mathrm{m}}$ With a +12 diopter lens (Aphakia)

report of any subjective visual or functional deteriorations.

Additionally, we estimated the lost patient in the follow-up with an OGI, as having a minimum of one subjective permanent impairment due to impaired accommodation after IOL implantation.

Altogether, eleven patients (six re-examined, four contacted by phone, and one lost in the follow-up) 
were evaluated to suffer a permanent visual or functional impairment (Table 3).

Permanent impairments were mainly caused by manual tools (9/11) and nails (4/5). All OGI (9/9) resulted in permanent impairment. Work tools comprised $10.3 \%(n=11)$ of all the permanently impaired cases (107), and 2.5\% $(n=26)$ of all the nonpermanently impaired cases (1044) among all eye injuries (1151). Work tools caused four times (=312\%-points) more permanently impaired cases than non-permanently impaired cases among all eye injuries (Table 4).

\section{Use of resources}

Fifteen patients were estimated to need a lifelong follow-up due to risk of post-traumatic glaucoma, retinal detachment, or permanent substantial symptoms. Work tool-related eye injuries caused 690 sick leave days, 59 of which were spent in a ward. Fourteen patients underwent 43 major surgeries (Table 5).

\section{Discussion}

To our knowledge, there are no recent follow-up studies focused solely on work tool-related eye injuries. This study describes the typical features of work tool-related eye injuries in HUEH district (1.55 million population). More than half of work toolrelated eye injuries had potentially severe diagnoses such as open globe injuries $(n=9)$ or contusions $(n=12)$, and all OGIs caused a permanent impairment. Work tools caused four times more permanently impaired cases $(10.3 \%)$ than non-permanently impaired cases $(2.5 \%)$ among all eye injuries. This figure is clearly higher than the corresponding amounts of other causes of eye injuries (Table 4). In this respect, work tool-related eye injuries are more prone to cause a permanent impairment being more serious than other causative factors in our previous studies [7-9, 18]. We showed that an eye injury by a nail most probably results in a permanent impairment (5/6 nail or nail gun injuries). Furthermore, manual tools $(n=27)$, rather than power tools $(10)$, caused most of the work tool-related injuries, and nine out of eleven permanently impaired cases were caused by manual tools (Tables 2, 3). However, Chen and colleagues reported that cutting tools/construction caused most consumer-related eye injuries (33\%) among 25-64-year-olds [4]. In our study, manual tools and related equipment were also the riskiest tools, as $33 \%$ of these $(9 / 27)$ caused a permanent impairment compared to $20 \%$ of power tools $(2 / 10)$.

One should, however, bear in mind that the type and the extent of eye injuries may vary according to the social and economic state, and level of industrial development of the country under study. These can eventually affect the characteristics, treatments, and outcomes of eye injuries [1-5, 19-22].

In our study, one patient suffered a retinal detachment (RD) between the follow-ups. This is in accordance with a study that described delayed-onset retinal detachment as late as 10 years after contusion or OGI [23]. Three re-examined patients at 6-year follow-up had a lower VA than in the first follow-up: one was phthitic, one had developed a cataract, and one patient was aphakic (Table 3). Surprisingly, we found no post-traumatic glaucoma in our series. Girkin et al. found a $3.4 \%$ incidence of post-traumatic glaucoma after ocular contusion [24]. Furthermore, a report suggested post-traumatic glaucoma after as long as 20 years following eye injury [25].

Our study has some limitations, however. First, we studied injuries presented only at HUEH, which may underestimate the number of minor injuries treated in the private sector or local care units. Nevertheless, we covered the more serious types of injuries correctly, as HUEH acts as the sole secondary and tertiary referral center in the area. Secondly, two patients were lost in follow-up, and all the patients did not attend the clinical re-examination. We did, however, gather reliable information on the subjective symptoms through a structured interview by phone from those who did not attend.

The strengths of our study include the 6-year follow-up time, and the fact that we provided data for all age groups and different levels of severity.

The results of this study may reflect the increasing popularity of the do-it-yourself (DIY) culture in Finland, and the lack of interest or responsibility in protecting one's own eyes by failing to take safety 
Table 4 Comparison of proportions of the permanently impaired and the non-permanently impaired cases between different causes of all eye injuries ${ }^{\mathrm{a}}$

\begin{tabular}{lcccccc}
\hline Cause of injury & Total\% $(n)$ & Impaired $\%(n)$ & Not impaired\% $(n)$ & CI $^{\mathrm{b}}(\%)$ & $p$ value & Difference $(\% \text {-point })^{\mathrm{c}}$ \\
\hline Work tools & $3.2(37)$ & $10.3(11)$ & $2.5(26)$ & $1.4-14.1$ & $<0.001$ & 312 \\
Fall & $4.7(54)$ & $13.1(14)$ & $3.8(40)$ & $2.2-16.3$ & $<0.001$ & 245 \\
Body part $^{\mathrm{d}}$ & $12.3(142)$ & $19.6(21)$ & $11.6(121)$ & $-0.3-16.3$ & $<0.05$ & 69 \\
Sports equipment $^{\text {Sticks }}$ & $12.9(149)$ & $15.9(17)$ & $12.6(132)$ & $-4.5-11.0$ & $\mathrm{NS}^{\mathrm{e}}$ & 26 \\
Chemicals & $6.2(71)$ & $6.5(7)$ & $6.1(64)$ & $-4.9-5.7$ & $\mathrm{NS}$ & 7 \\
Others & $11.5(132)$ & $4.7(5)$ & $12.2(127)$ & $-12.5-2.5$ & $<0.05$ & -61 \\
Total & $49.2(566)$ & $29.9(32)$ & $51.2(534)$ & $0.1-0.3$ & $<0.001$ & -42 \\
\hline
\end{tabular}

${ }^{\mathrm{a}}$ Values of non-work tool eye injuries are from previous Helsinki Ocular Trauma Studies: (Haavisto et al. [7], Leivo et al. [18], and Sahraravand et al. [7, 8]

${ }^{\mathrm{b}} 95 \%$ of Confidence-Interval

${ }^{\mathrm{c}}$ Difference of the permanently impaired versus the non-permanently impaired in percentage points in each group

${ }^{\mathrm{d}}$ Body part as the cause of eye injury (= human inflicted eye injuries)

eNot significant

Table 5 Resource use of work tool-related eye injuries

\begin{tabular}{llllll}
\hline & Patients $(n)$ & Mean & Median & Range & Total \\
\hline Activity restriction (days) & 31 & 31.1 & 14 & $0-215$ & 964 \\
Hospitalization (days) & 11 & 5.4 & 4 & $2-15$ & 59 \\
Major surgeries (operations) & 14 & 3.1 & 3 & $1-9$ & 43 \\
Outpatient visits (visits) & 37 & 4.1 & 2 & $1-19$ & 151 \\
Sick leave (days) & 30 & 23 & 7 & $0-215$ & 690 \\
\hline
\end{tabular}

standards seriously when working with tools. Thirtyone patients reported not wearing safety glasses, and we assume that there would be fewer and less serious injuries if proper protective eyewear were used, as it is reported that ninety percent of the eye injuries could be prevented by wearing protective eyewear [26].

In conclusion, this study shows the characteristics of work tool-related eye injuries and presents the risk factors. We demonstrate that work tools cause serious eye injuries specially among younger people (33/ $37=89 \%)$. Four patients $(11 \%)$ were legally blinded. Forty-three major operations were needed for 14 $(38 \%)$ patients, fifteen patients $(41 \%)$ needed a lifelong follow-up, and eleven patients (30\%) suffered a permanent visual or functional impairment. This information may have far-reaching relevance in future research to find the means with which to prevent such injuries.
Acknowledgements Open access funding provided by University of Helsinki including Helsinki University Central Hospital.

Funding This study was supported by grants from The Mary and George C. Ehrnrooth Foundation, The Finnish Ophthalmological Foundation, The Finnish Eye and Tissue Bank Foundation, The Chancellor's Grant of Helsinki University, Friends of the Blind-registered association, and Helsinki University Hospital Scientific Fund.

\section{Compliance with ethical standards}

Conflict of interest None of the following authors have any proprietary interests or conflicts of interest related to this submission: Ahmad Sahraravand, Anna-Kaisa Haavisto, Päivi Puska, and Tiina Leivo (all from Ophthalmology, University of Helsinki and Helsinki University Hospital, Helsinki, Finland).

Ethical approval All procedures performed in studies involving human participants were in accordance with the ethical standards of the institutional and/or national research committee and with the 1964 Helsinki Declaration and its later amendments or comparable ethical standards. 
Informed consent Informed consent was obtained from all individual participants included in the study.

Open Access This article is licensed under a Creative Commons Attribution 4.0 International License, which permits use, sharing, adaptation, distribution and reproduction in any medium or format, as long as you give appropriate credit to the original author(s) and the source, provide a link to the Creative Commons licence, and indicate if changes were made. The images or other third party material in this article are included in the article's Creative Commons licence, unless indicated otherwise in a credit line to the material. If material is not included in the article's Creative Commons licence and your intended use is not permitted by statutory regulation or exceeds the permitted use, you will need to obtain permission directly from the copyright holder. To view a copy of this licence, http:// creativecommons.org/licenses/by/4.0/.

\section{References}

1. Desai P, MacEwen CJ, Baines P, Minassian DC (1996) Epidemiology and implications of ocular trauma admitted to hospital in Scotland. J Epidemiol Community Health 50:436-441

2. Desai P, Morris DS, Minassian DC, MacEwen CJ (2015) Trends in serious ocular trauma in Scotland. Eye (Lond) 29(5):611-618

3. Iftikhar M, Latif A, Farid UZ, Usmani B, Canner JK, Shah SMA (2019) Changes in the incidence of eye trauma hospitalizations in the United States From 2001 Through 2014. JAMA Ophthalmol. 137(1):48-56

4. Chen AJ, Chan JJ, Linakis JG, Mello MJ, Greenberg PB (2014) Age and consumer product-related eye injuries in the United States. Rhode Island Med J 97(1):44-48

5. Chen AJ, Kim JG, Linakis JG, Mello MJ, Greenberg PB (2013) Eye injuries in the elderly from consumer products in the United States: 2001-2007. Graefes Arch Clin Exp Ophthalmol 251(3):645-651

6. Saari KM, Parvi V (1984) Occupational eye injuries in Finland. Acta Ophthalmol 161:17-28

7. Sahraravand A, Haavisto AK, Holopainen JM, Leivo T (2017) Ocular traumas in working age adults in FinlandHelsinki Ocular Trauma Study. Acta Ophthalmol 95(3):288-294

8. Sahraravand A, Haavisto AK, Holopainen JM, Leivo T (2018) Ocular traumas in the Finnish elderly-Helsinki Ocular Trauma Study. Acta Ophthalmol 96(6):616-622

9. Haavisto AK, Sahraravand A, Holopainen JM, Leivo T (2017) Paediatric eye injuries in Finland-Helsinki eye trauma study. Acta Ophthalmol 95(4):392-399

10. Saari KM, Aine E (1984) Eye injuries in agriculture. Acta Ophthalmol 62(Suppl 161):42-51
11. Burger BM, Kelty PJ, Bowie EM (2009) Ocular nail gun injuries: epidemiology and visual outcomes. J Trauma 67(6):1320-1322

12. Kelly SP, Reeves GM (2012) Penetrating eye injuries from writing instruments. Clin Ophthalmol 6:41-44

13. Statistics Finland PX-Web statistical database (2018) Population structure according to gender and age between 19722017 http://pxnet2.stat.fi/PXWeb/pxweb/fi/StatFin/StatFin vrm_vaerak/statfin_vaerak_ pxt_004.px/?rxid = 382549d17e83-4e29-af80-08030cd6304e. Accessed 24 Aug 2018

14. Gerstenblith A, Rabinowitz M (2012) The wills eye manual, 6th ed office and emergency room diagnosis and treatment of eye disease. Lippincott Williams \& Wilkins, Philadelphia

15. Recchia FM, Saluja RK, Hemmel K, Jeffers JB (2002) Outpatient management of traumatic microhyphema. J Ophthalmol 109:1465-1470

16. Tsai R, Denniston A, Murray P, Huang J, Aldad T (2011) American handbook of ophthalmology. Oxford University Press, Oxford

17. Walton W, Hagen V, Grigorian R, Zarbin M (2002) Management of traumatic hyphema. Surv Ophthalmol 47:297-334

18. Leivo T, Haavisto AK, Sahraravand A (2015) Sports-related eye injuries: the current picture. Acta Ophthalmol 93(3):224-231

19. Chen SY, Fong PC, Lin SF, Chang CH, Chan CC (2009) A case-crossover study on transient risk factors of work-related eye injuries. Occup Environ Med 66:517-522

20. Forrest KY, Cali JM (2009) Epidemiology of lifetime workrelated eye injuries in the U.S. population associated with one or more lost days of work. Ophthalmic Epidemiol 16:156-162

21. Ngo CS, Leo SW (2008) Industrial accident-related ocular emergencies in a tertiary hospital in Singapore. Singapore Med J 49:280-285

22. Zghal-Mokni I, Nacef L, Kaoueche M, Letaief I, Bouguila H, Jeddi A et al (2007) Epidemiology of work—related eye injuries. Tunis Med 85:576-579

23. Rouberol F, Denis P, Romanet JP, Chiquet C (2011) Comparative study of 50 early- or late-onset retinal detachments after open or closed globe injury. Retina 31(6):1143-1149

24. Girkin CA, JrG McGwin, Long C, Morris R, Kuhn F (2005) Glaucoma after ocular contusion: a cohort study of the United States Eye Injury Registry. J Glaucoma 14(6):470-473

25. Sihota R, Sood NN, Agarwal HC (1995) Traumatic glaucoma. Acta Ophthalmol Scand 73(3):252-254

26. American Academy of Ophthalmology, AAO, Diseases \& Conditions, Eye Health A-Z, Preventing eye injuries (2016). Web site. https://www.aao.org/eye-health/diseases/preventinginjuries. Accessed 10 Dec 2018

Publisher's Note Springer Nature remains neutral with regard to jurisdictional claims in published maps and institutional affiliations. 